\title{
Transcutaneous immunization induces mucosal CTLs and protective immunity by migration of primed skin dendritic cells
}

\author{
Igor M. Belyakov, ${ }^{1}$ Scott A. Hammond, ${ }^{2}$ Jeffrey D. Ahlers, ${ }^{1}$ Gregory M. Glenn, ${ }^{2}$ \\ and Jay A. Berzofsky'
}

${ }^{1}$ Molecular Immunogenetics and Vaccine Research Section, Vaccine Branch, National Cancer Institute, National Institutes of Health, Bethesda, Maryland, USA 2IOMAI Corporation, Gaithersburg, Maryland, USA.

\begin{abstract}
Transcutaneous immunization (TCI), the application of vaccines on the skin, induces robust systemic and mucosal antibodies in animal models and in humans. The means by which mucosal immune responses to vaccine antigens are elicited by TCI has not been well characterized. We examined the effect of TCI with an HIV peptide vaccine on the induction of mucosal and systemic CTL responses and protective immunity against mucosal challenge with live virus in mice. Robust HIV-specific CTL responses in the spleen and in the gut mucosa were detected after TCI. The responses were dependent upon the addition of an adjuvant and resulted in protection against mucosal challenge with recombinant vaccinia virus encoding HIV gp160. Although it is clear that adjuvant-activated DCs migrated mainly to draining lymph nodes, coculture with specific T cells and flow cytometry studies with DCs isolated from Peyer's patches after TCI suggested that activated DCs carrying skin-derived antigen also migrated from the skin to immune-inductive sites in gut mucosa and presented antigen directly to resident lymphocytes. These results and previous clinical trial results support the observation that TCI is a safe and effective strategy for inducing strong mucosal antibody and CTL responses.
\end{abstract}

\section{Introduction}

Major entry points for many infections occur at a mucosal surface: gastrointestinal (e.g., HIV and polio virus), respiratory (e.g., influenza and adenovirus), or genital (e.g., HIV and herpes simplex virus). Thus, the induction of mucosal immune responses and prevention of mucosal transmission are critical goals for many vaccines (1-6). In the case of HIV and other viral infections, control of the viral load is dependent upon potent $\mathrm{CD}^{+} \mathrm{T}$ cell responses, including mucosal CTLs at the site of viral infection (7-11). The best way to induce protective immunity against a mucosal challenge in mice and nonhuman primates is immunization through a mucosal route, while systemic immunization can provide only partial mucosal protection $(4,9,12)$.

Transcutaneous immunization (TCI), the application of antigen and adjuvant onto the skin to induce antigen-specific immune responses, is a novel immunization strategy that induces robust mucosal IgG and secretory IgA responses in both mice and humans (13-19) and protective immunity against mucosal challenge with toxin $(13,14)$ or live virus $(19)$. TCI also induces systemic cell-mediated immunity to peptide $(20,21)$ and whole protein $(16,21-23)$, but little information has been generated describing the mucosal cellular responses induced by skin immunization (18).

Adjuvants are required for the induction of potent immune responses to coadministered antigens by TCI; the main adjuvants

Nonstandard abbreviations used: Alexa Fluor 488 covalently coupled to LT (AF-LT); cholera toxin (CT); complete medium (CM); draining lymph node (DLN); heat-labile enterotoxin of enterotoxigenic Escherichia coli (LT); magnetic cell sorting (MACS); Peyer's patch (PP); phycoerythrin (PE); spleen (SP); transcutaneous immunization (TCI).

Conflict of interest: S.A. Hammond and G.M. Glenn have financial interests in IOMAI Corp.

Citation for this article: J. Clin. Invest. 113:998-1007 (2004)

doi:10.1172/JCI200420261. are ADP-ribosylating enterotoxins that include cholera toxin (CT) and the heat-labile enterotoxin of enterotoxigenic Escherichia coli (LT). TCI is not limited to ADP-ribosylating enterotoxins as the sole source of compounds available with adjuvant properties active in the context of the skin. Many other molecules have adjuvant activity when applied to the skin (24). In their native form, CT and LT cannot be readily administered orally in humans due to their enterotoxicity, but they have been shown to be safe in animal and human skin immunization studies $(13,14,16-18,24-26)$.

Skin immunization utilizes potent bone marrow-derived DCs that are resident in the outer epidermal layers of skin, such as Langerhans cells. These DCs provide immunosurveillance functions, and when they are activated by microorganisms, their products, or inflammatory cytokines, migrate out of the skin to the draining lymph nodes (DLNs) and induce strong effector antigenspecific responses by B and T lymphocytes. In the context of TCI, the addition of immunostimulating agents (microbial toxin or inflammatory signal) at the site of antigen administration provides the necessary activation signal for the DCs to mature, express high levels of costimulatory molecules, secrete cytokines, and become potent antigen-presenting cells (APCs) capable of priming immune responses to the coadministered antigen. DCs are loaded and stimulated in vivo by topical application of vaccines. TCI thereby directly utilizes the most potent of immune activators, DCs, in a manner similar to DC immunotherapy but without the labor-intensive, cumbersome, and individualized ex vivo production and antigen-loading of DCs with subsequent administration back into the patient (27).

Because TCI induces mucosal antibody and can induce robust systemic cell-mediated immune responses, we hypothesized that TCI should also induce cell-mediated immune responses in the mucosa. Therefore, in this study we investigated and characterized the cell-mediated systemic and mucosal immune responses 
induced by a TCI regimen consisting of an HIV peptide construct with CT or LT or CPG oligodeoxynucleotides as adjuvants. These CTL responses were compared with responses induced by intrarectal immunization and by a combined regimen consisting of intrarectal and transcutaneous routes of immunization. We also analyzed the potency of the TCI-induced immune response induced against a live viral challenge and defined a novel mechanism for the induction of the mucosal CTLs induced by skin immunization.

\section{Methods}

Animals. Female BALB/c or C57BL/6 mice were purchased from Frederick Cancer Research Center (Frederick, Maryland, USA), or Charles River Laboratories Inc. (Wilmington, Massachusetts, USA), maintained in a specific pathogen-free microisolator environment, and used at 6-25 weeks of age. Mice received food and water ad libitum. All procedures with animals were conducted in accordance with the institutionally approved protocols.

Antigens and adjwants. The peptide PCLUS3-18IIIB (KQIINMWQEVGKAMYAPPISGQIRRIQRGPGRAFVTIGK) consists of the multideterminant helper segment PCLUS3 (KQIINMWQEVGKAMYAPPISGQIR) (28), derived from the CD4 binding domain of HIV-1 IIIB, combined with the immunodominant CTL epitope presented by $\mathrm{H}-2 \mathrm{D}^{\mathrm{d}}$ in BALB/c mice, called P18 IIIB (RIQRGPGRAFVTIGK) (29), derived from the V3 loop of the IIIB strain of HIV-1, in a single continuous peptide. The oligodeoxynucleotide $5^{\prime}$ TCCATGACGTTCCTGACGTT-3' contains a CPG motif with immunostimulatory properties in the mouse (30). CT (List Biologicals, Campbell, California, USA) and LT (Berna Biotech AG, Bern, Switzerland) are ADP-ribosylating enterotoxins with adjuvant activity and no toxic side effects when applied to the skin. Alexa Fluor 488 (Molecular Probes, Eugene, Oregon, USA) was covalently coupled to LT (AF-LT) as described (18).

Transcutaneous immunization. Mice were immunized on the skin as described $(18,24)$. Briefly, each animal was shaved on the dorsum or abdomen and allowed to rest for 48 hours. Mice were anesthetized in the hind thigh intramuscularly or intraperitoneally with a ketamine-xylazine mixture to prevent self-grooming (i.e., oral immunization). For the experiments presented in Figures 1 and 2, the exposed skin surface was hydrated with saline-drenched gauze for 5-10 minutes and then was lightly blotted with dry gauze prior to immunization. For the experiments displayed in Figures 3-8, hydrated skin was buffed with emery paper to disrupt the stratum corneum and to enhance antigen and adjuvant delivery. Disruption of the stratum corneum leaves the epidermis intact, increases the efficiency of antigen and adjuvant delivery, and subsequently elicits stronger immune responses to the vaccine than does simple hydration alone with a similar dosing regimen (26). Each animal received either $25-100 \mu \mathrm{l}$ of immunizing solution applied onto the shaved skin or the ventral surface of the ear for 1 hour, or a $1-\mathrm{cm}^{2}$ gauze patch containing $25 \mu \mathrm{l}$ of immunizing solution covered by a semiocclusive backing and placed on the shaved skin for up to 18 hours. The animals were then extensively washed, tails down, under running tap water for approximately 30 seconds and patted dry.

Mice were immunized intrarectally with PCLUS3-18IIIB and LT or CT. A mixture of peptide and adjuvant ( $150 \mu \mathrm{l}$ total) was injected intrarectally through an umbilical catheter inserted about $4 \mathrm{~cm}$ deep from the anus in mice sedated by inhalation anesthesia (methoxyflurane; Pitman-Moore Inc., Mundelein,Ill) (31).

Cell isolation. Spleens (SPs), inguinal lymph nodes (LNs), superficial cervical LNs, and mesenteric LNs were aseptically removed and pooled, and single-cell suspensions were prepared by gentle passage of the tissue through sterile mesh screens $(100 \mu \mathrm{m})$. For SP cell suspensions, erythrocytes were lysed with Tris-buffered ammonium chloride and the remaining cells were washed extensively in RPMI 1640 (Biowhittaker, Walkersville, Maryland, USA) containing 2\% fetal bovine serum (Gemini, Woodland, California, USA) (32).

Peyer's patches (PPs) were carefully excised from the wall of the small intestine, pooled, and dissociated into single-cell suspensions by enzymatic digestion with collagenase type VIII $(300 \mathrm{U} / \mathrm{ml}$; Sigma-Aldrich, St. Louis, Missouri, USA) and DNAse I $(3 \mathrm{U} / \mathrm{ml}$; Sigma-Aldrich) for $60 \mathrm{~min}$. Cells were collected, washed, and resuspended in complete medium (CM), which is RPMI-1640 supplemented with $10 \%$ fetal bovine serum, $10 \mathrm{U}$ penicillin (Invitrogen, Carlsbad, California, USA), $100 \mu \mathrm{g} / \mathrm{ml}$ streptomycin (Invitrogen), $2 \mathrm{mM}$ glutamine (Invitrogen), $50 \mu \mathrm{M} \beta$-mercaptoethanol (Invitrogen), and $20 \mathrm{mM}$ HEPES (Biowhittaker). Cells were then layered onto a discontinuous density gradient containing $75 \%$ and $40 \%$ Percoll (Pharmacia Inc., Uppsala, Sweden) and were centrifuged at $600 \mathrm{~g}$ for 25 minutes. The interface band containing cells between the $75 \%$ and $40 \%$ Percoll was carefully removed and washed with RPMI 1640 containing 2\% fetal bovine serum. The resulting population was more than $90 \%$ viable lymphocytes, with a cell yield of $1 \times 10^{7}$ lymphocytes/mouse. Most PP CD3 ${ }^{+} \mathrm{T}$ cells isolated from normal mice were $\mathrm{CD}^{+}$, while $\mathrm{CD}^{+}{ }^{+} \mathrm{CD} 8^{+} \mathrm{T}$ cells were less frequent. Collagenase VIII digestion does not alter the expression of CD3, CD4, or CD8 on splenic T cells treated with this enzyme (2).

Single-cell suspensions of lung lymphocytes were isolated by DNAse $(3,500 \mathrm{U} / \mathrm{ml})$ and collagenase VIII $(75 \mathrm{U} / \mathrm{ml})$ digestion of pooled perfused lung tissue at $37^{\circ} \mathrm{C}$ for 2 hours. Cells were subjected to centrifugation on Ficoll-Paque Plus solution at $400 \mathrm{~g}$ for $30 \mathrm{~min}$ (33).

CD11 $c^{+}$APC populations were isolated from inguinal $L N$ and PP single cell suspensions using magnetic cell sorting (MACS) antimouse CD11c MicroBeads (Miltenyi Biotec, Bergish-Gladbach, Germany). Single-cell suspensions were incubated with mouse immunoglobulin $(1 \mu \mathrm{g}$ per $500 \mu \mathrm{l})$ to block Fc receptor binding sites before anti-mouse CD11c MicroBeads were added. CD11c ${ }^{+}$ cells were positively selected by magnetic retention, eluted by removal of the magnetic field, and washed with CM.

Cytotoxic T lymphocyte assay. Single-cell suspensions of pooled SP, lung or PP cells were activated and expanded by culture with antigen for 6 or 7 days and were used as the effector cell population in the assay. Cells were cultured at a density of $5 \times 10^{6} \mathrm{per} / \mathrm{ml}$ in 12 well culture plates with $1 \mu \mathrm{M}$ of the synthetic CTL epitope peptide P18-I10 (I10; RGPGRAFVTI), the minimal epitope of P18 IIIB, in CM (31). Three days after the culture was initiated, a medium containing 10\% concanavalin A supernatant (T-stim; Collaborative Biomedical Products, Bedford, Massachusetts, USA) was added as a source of IL-2. Cytolytic activity of the CTL cultures was measured in a 4-hour ${ }^{51}$ Cr-release assay using labeled P815 targets cells that had been cultured in the presence or absence of P18-I10 peptide $(1 \mu \mathrm{M})$. The percent specific ${ }^{51} \mathrm{Cr}$ release was calculated as $100 \times$ (experimental release - spontaneous release) / (maximum release - spontaneous release). Maximum release was determined from supernatants of cells that were lysed by the addition of 5\% Triton-X 100. Spontaneous release was determined from target cells incubated without added effector cells (34).

Fluorescent antibody staining. Single-cell suspensions of inguinal LNs, cervical LNs, mesenteric LNs, SP, and PPs in PBS plus $1 \%$ bovine serum albumin (BSA) (Sigma-Aldrich) were blocked for 20 


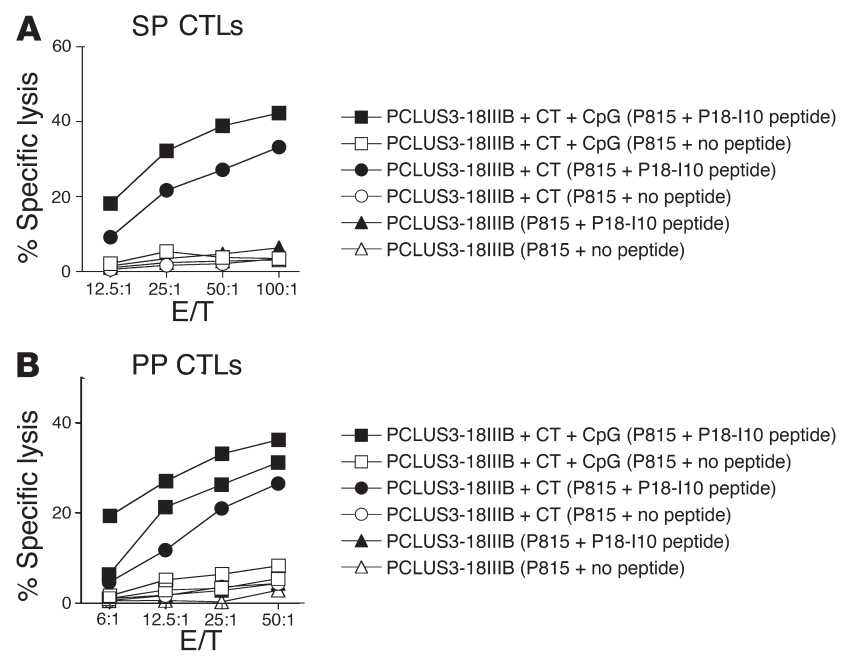

Figure 1

Induction of CTL responses in SP and PPs after TCI with HIV peptide and adjuvant. BALB/c mice $(n=5)$ were immunized twice 3 weeks apart with $50 \mu \mathrm{g}$ of PCLUS3-18IIIB peptide alone (triangles), with $50 \mu \mathrm{g}$ CT as an adjuvant (circles), or with $50 \mu \mathrm{g} \mathrm{CT}$ and $50 \mu \mathrm{g} \mathrm{CpG}$ as adjuvants (squares). SP (A) and PP (B) cells from immunized mice were incubated in vitro with $1 \mu \mathrm{M}$ P18-I10 peptide for 7 days before cytolytic activity was measured in a 4-hour ${ }^{51} \mathrm{Cr}$-release assay against P815 target cells alone (open symbols) or pulsed with P18-I10 peptide (filled symbols). E/T, effector-to-target ratio.

minutes on ice with Fc block (anti-CD16/CD32; BD Biosciences, San Diego, California, USA) and were then stained with antiCD3-CyChrome (BD Biosciences), anti-CD19-peridinine chlorophyll protein-Cy5.5 (BD Biosciences), anti-CD11c-allophycocyanin (BD Biosciences), anti-CD40-phycoerythrin (PE) (BD Biosciences), anti-H-2 I-A $\mathrm{A}^{\mathrm{d}}-\mathrm{PE}$ (BD Biosciences), and/or Dead Red (Molecular Probes) for 30 minutes. After being washed with cold PBS plus $1 \%$ BSA, the cells were analyzed by flow cytometry with the $\mathrm{CD}^{+}, \mathrm{CD} 9^{+}$, and dead cells removed from the analysis.

CTL lines. CTL lines specific for P18-I10 (the minimal epitope of P18IIIB) and P18-89.6A9, the homologous but non-cross-reactive epitope of the 89.6 strain of HIV-1, were prepared as described (29, 31). Mice were immunized intraperitoneally with $1 \times 10^{7} \mathrm{PFU}$ of recombinant vaccinia virus carrying the sequences encoding the HIV envelope protein of strain IIIB. Three weeks after immunizations, mice were euthanized, SPs were removed, and single-cell suspensions of SP cells were restimulated with $0.001 \mu \mathrm{M}$ (high-avidity CTLs) or $10 \mu \mathrm{M}$ (low-avidity CTLs) of P18-I10 or P18-89.6A9 peptide. The cell lines were restimulated weekly with irradiated syngeneic SP cells pulsed with P18-I10 peptide for 1 hour before irradiation. Cells were cultivated in 24-well plates in CM in the presence of $10 \%$ T-stim.

IFN- $\gamma$ ELISA. Concentrations of IFN- $\gamma$ in culture supernatants were measured using a murine cytokine enzyme-linked immunosorbent assay (ELISA), the Mouse IFN gamma ELISA MiniKit (Endogen, Cambridge, Massachusetts, USA), as per the manufacturer's instructions.

\section{Results}

TCI induces systemic and mucosal CTLs that are protective against mucosal live virus challenge. To study the induction of mucosal and systemic CTL responses after TCI, we immunized BALB/c mice twice with an HIV peptide construct (PCLUS3-P18IIIB; $50 \mu \mathrm{g} /$ mouse) in the presence or absence of $\mathrm{CT}$ and $\mathrm{CPG}$ oligodeoxynucleotide as adjuvants. CTL responses were assayed 2 weeks after the last immunization (day 35) (Figure 1). We found that TCI with HIV peptide with CT and CpG as adjuvants can induce P18IIIB-I10-specific $\mathrm{CD}^{+}$CTLs in PPs of the intestine (Figure 1B) as well as in the SP (Figure 1A). In multiple previously published studies, we found that subcutaneous immunization with peptide did not elicit a significant CTL response in the PPs $(2,12)$. An HIV peptide construct with $C T$ as an adjuvant but without $\mathrm{CPG}$ was able to induce CTLs both in the SP (Figure 1A) and in PPs (Figure 1B). However, the level of CTL responses in the gut and in the SP was greater in magnitude in the groups with $\mathrm{CPG}$ and $\mathrm{CT}$ as adjuvants (Figure 1). TCI with PCLUS3-P18IIIB alone did not induce mucosal (data not shown) or systemic (Figure 1A) CTLs. Because the addition of CpG oligodeoxynucleotide directs a more Th1-like response (i.e., CTLs) $(30,35,36)$ and the addition of the oligodeoxynucleotide showed some potential enhancing effects on the cellular response after TCI, the CpG oligodeoxynucleotide was included in subsequent immunization regimens unless otherwise noted.

To determine the optimal skin immunization site for inducing maximal systemic and mucosal CD8 ${ }^{+} \mathrm{CTL}$ responses, we compared the effects of TCI in mice immunized on the back, abdomen, or ear. Systemic (SP) and mucosal (PP) CTL responses were measured for all three anatomical sites of skin immunization (Figure 2). The highest CTL response in both mucosal and systemic sites was observed after TCI on the back, although TCI on the abdomen gave a comparable level of PP CTL response, albeit with a higher background.

To determine the protective efficacy of the mucosal immune response induced by TCI using the HIV peptide with CT or LT as an adjuvant, we challenged immunized mice intrarectally with live vaccinia virus carrying the gene encoding HIV-1 IIIB gp160 (37). Six days after the mucosal challenge with virus, mice were sacrificed and their ovaries were removed and assayed for virus titer (12). TCI using the HIV peptide with CT or LT as an adjuvant partially protected mice against an intrarectal challenge with HIV-recombinant vaccinia virus (Figure 3), as shown by a 2-log reduction in viral PFU in the ovaries of TCI mice compared with those of mice immunized with adjuvant alone. TCI using the HIV peptide with CT or LT as an adjuvant was equally effective for protection against mucosal challenge (Figure 3). The efficacy of the TCI results contrasts with sub-
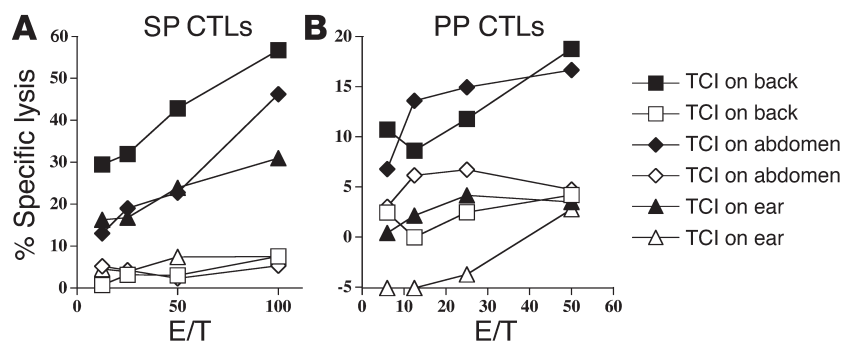

Figure 2

$(\mathbf{A}$ and $\mathbf{B}) \mathrm{TCl}$ at multiple anatomic skin sites elicits systemic $(\mathbf{A})$ and mucosal (B) CTL responses. BALB/c mice $(n=5)$ were skin-immunized on the back (squares), abdomen (diamonds), or ear (triangles) with $100 \mu \mathrm{g}$ PCLUS3-18IIIB peptide with $50 \mu \mathrm{g}$ CT and $50 \mu \mathrm{g} \mathrm{CpG}$ as adjuvants. Immunizations occurred on weeks $0,1,3$, and 5 . SP (A) and PP (B) cytolytic activity was measured in a ${ }^{51} \mathrm{Cr}$-release assay against P815 target cells alone (open symbols) or pulsed with P18-I10 peptide (filled symbols). 


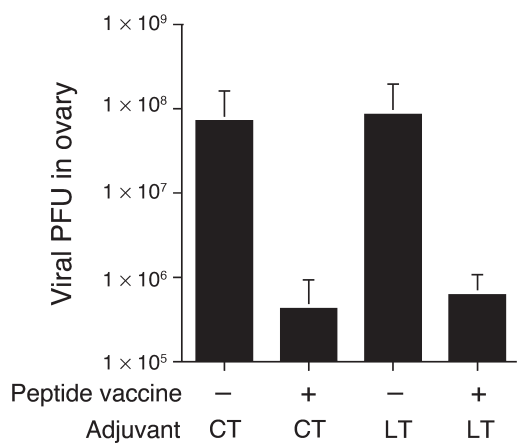

Figure 3

$\mathrm{TCl}$ with peptide and adjuvant induces protective immunity against intrarectal recombinant vaccinia challenge. BALB/c mice $(n=5)$ were skin-immunized three times at 2-week intervals with $100 \mu \mathrm{g}$ PCLUS3IIIB peptide alone or with $25 \mu \mathrm{g}$ CT or $25 \mu \mathrm{g}$ LT as an adjuvant. Two weeks after the final immunization, mice were challenged intrarectally with $1 \times 10^{7} \mathrm{PFU}$ of vaccinia virus carrying the gene encoding HIV-1 gp160 from the IIIB isolate (vPE16). Six days after the challenge with recombinant vaccinia virus, the mice were euthanized and their ovaries were removed, homogenized, sonicated, and assayed for VPE16 by plating of serial tenfold dilutions on monolayers of BSC-2 indicator cells (12). Cells were stained with crystal violet and the resulting plaques were counted for each dilution. The minimal detectable level of virus was 100 PFU. Bars: SEM of five mice per group. The difference between unvaccinated and vaccinated with either adjuvant is significant at $P<0.01$ by Student's $t$ test.

cutaneous immunization with peptide and incomplete Freund's adjuvant, which does not protect against intrarectal challenge (12).

Transcutaneous and intrarectal immunization regimens are effective strategies for priming systemic and mucosal CTL responses. To compare priming and boosting regimens with various transcutaneous and intrarectal immunization sequences, we analyzed the CTL response in mucosal and systemic compartments after four immunizations with an interval of 2 weeks between each immunization (Figure 4). HIV-specific CTL responses in the SP and PPs were studied 2 weeks after the last immunization. Mice were immunized four times transcutaneously; three times transcutaneously followed by once intrarectally; or once intrarectally followed by three times transcutaneously. We found that all three regimens induced a highly comparable level of CTL activity in the SP (Figure 4A), although the HIV-specific CTL response in the SP after one intrarectal followed by three transcutaneous immunizations may have been marginally weaker than that after four transcutaneous immunizations or three transcutaneous plus one intrarectal immunization (Figure $4 \mathrm{~A})$. In contrast, the rank order of HIV-specific CTL responses in the PPs of the three groups of immunized animals differed (Figure 4B). The highest CTL response in the PPs was found in mice that received three transcutaneous immunizations and one intrarectal booster immunization. In the groups of animals treated with four transcutaneous immunizations or one intrarectal followed by three transcutaneous immunizations, HIV-specific CTL responses were observed at the highest effector/target ratio only and were significantly lower than in mice with three transcutaneous immunizations followed by one intrarectal booster.

In view of this better response when transcutaneous immunization was given first, we investigated several prime and boost strategies in which transcutaneous immunization was used to prime or boost immune responses. Mice were immunized with HIV peptide,
$\mathrm{CT}$, and $\mathrm{CpG}$ oligodeoxynucleotide twice at 2-week intervals and were sacrificed 2 weeks after the last immunization to analyze their CTL responses to HIV peptide in PPs (Figure 5A), SP (Figure 5B), and lung (Figure 5C). The regimens that the mice received included transcutaneous plus intrarectal immunization (group 1); two transcutaneous immunizations (group 2); subcutaneous plus intrarectal immunization (group 3); intraperitoneal plus intrarectal immunization (group 4); two intrarectal immunizations (group 5); and a single intrarectal immunization without boosting (group 6). We found the highest HIV-specific CTL response in the PPs after intrarectal prime and intrarectal boost immunizations (Figure 5A). Animals in group 1 (transcutaneous prime and intrarectal boost) and group 2 (transcutaneous prime and transcutaneous boost) also had a significant CTL response in the PPs. The other prime and boost strategies did not induce a mucosal CTL response. The HIVspecific CTL response in the systemic circulation (SP) was optimal after intraperitoneal priming immunization and intrarectal boost (Figure 5B). However, transcutaneous immunization as a priming immunization with transcutaneous or intrarectal boost also induced a significant CTL response in the SP.

We also studied the HIV-specific CTL response in the lung after immunizing mice twice transcutaneously, priming with transcutaneous immunization and boosting intrarectally, or immunizing twice intrarectally (Figure 5C). Two weeks later we studied the HIV-

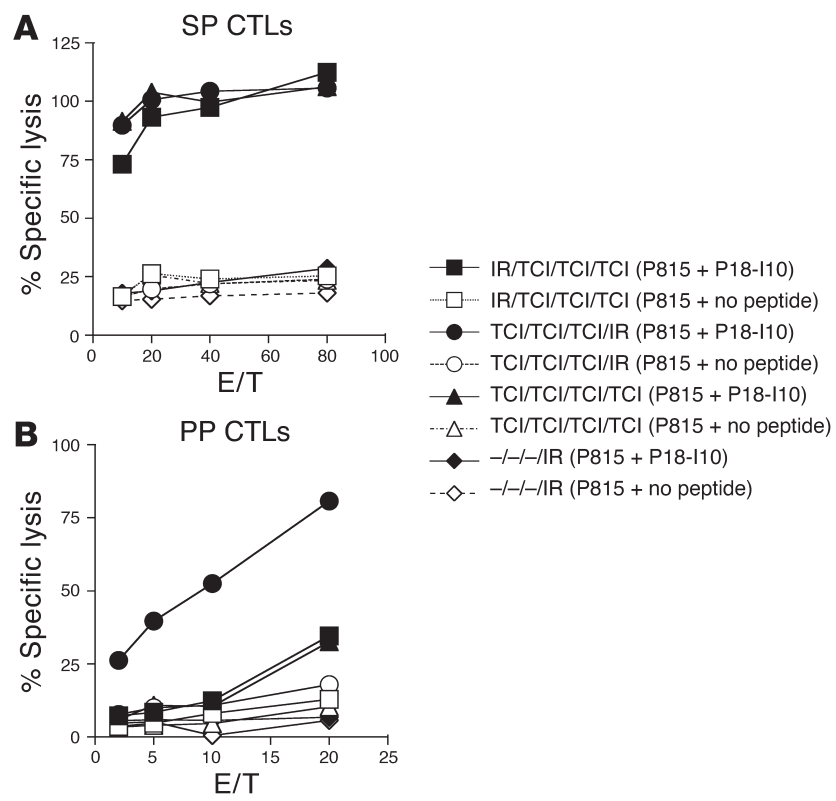

Figure 4

Prime and boost strategy using skin and intrarectal immunization regimens induces systemic and mucosal CTLs. BALB/c mice $(n=5)$ were immunized four times at 2-week intervals with no treatment or with 50 $\mu \mathrm{g}$ PCLUS3-IIIB peptide, $50 \mu \mathrm{g} \mathrm{CT}$, and $50 \mu \mathrm{g} \mathrm{CpG}$ by the indicated route of administration: one intrarectal and then three transcutaneous immunizations (IR/TCl/TCl/TCl); three transcutaneous and then one intrarectal immunization ( $\mathrm{TCl} / \mathrm{TCl} / \mathrm{TCl} / \mathrm{IR})$; four transcutaneous immunizations $(\mathrm{TCl} / \mathrm{TCl} / \mathrm{TCl} / \mathrm{TCl})$; or no treatment during the first three immunization intervals and an intrarectal immunization at the fourth interval $(-/-/-/ I R)$. On day 4 after the cell culture was established, CD8+ CTLs were purified by gradient centrifugation. Cytolytic activity of pooled SP (A) and PP (B) cells was measured in a ${ }^{51}$ Cr-release assay against P815 target cells alone (open symbols) or pulsed with P18-I10 peptide (filled symbols). 

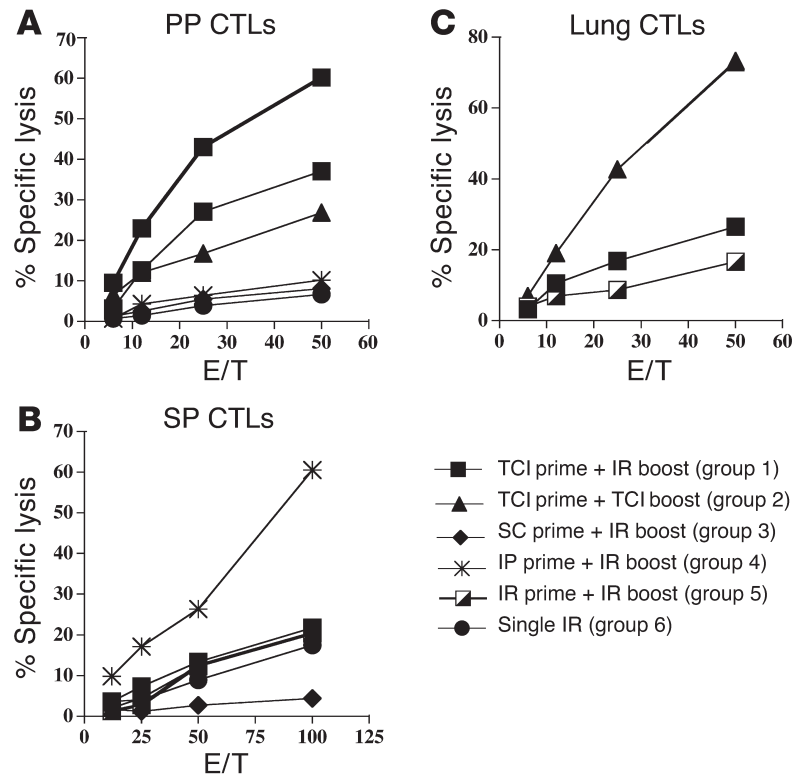

\footnotetext{
- TCl prime + IR boost (group 1)

— TCl prime + TCl boost (group 2)

$\_$SC prime + IR boost (group 3)

* IP prime + IR boost (group 4)

$\rightarrow-$ IR prime + IR boost (group 5)

- Single IR (group 6)
}

specific CTL response in the lung. We found the strongest CTL response in the lung after transcutaneous priming and transcutaneous boosting, while transcutaneous priming and intrarectal boosting also induced a CTL response in the lung (Figure 5c). Taken together, these results suggested that TCI was an effective means of antigen delivery to induce CTL responses systemically (i.e., SP) as well as in the gut (i.e., PP) and the lower respiratory tract (i.e., lung).

After TCI, APCs traffic to the gut mucosa, present skin-derived antigen to CTLs, and have upregulated activation markers. Although TCI clearly induced strong mucosal immune responses, the mechanism by which these responses were initiated was unknown. Three models were hypothesized based on known paradigms to explain these observations: after TCI, (a) APCs traffic to the regional DLNs and activate resident $T$ cells, and then the $T$ cells migrate to mucosal sites; (b) APCs traffic directly to the inductive sites of the mucosa

\section{Figure 6}

CD11c-enriched cells isolated from inguinal LNs and PPs of skinimmunized mice have acquired antigen that activates high- or lowavidity CTLs ex vivo. (A-D) Mice were immunized transcutaneously with $50 \mu \mathrm{g} \mathrm{LT}$ or with $50 \mu \mathrm{g}$ LT and $50 \mu \mathrm{g}$ PCLUSS3-18IIIB peptide and were sacrificed 24 hours after immunization. Pooled inguinal $L N$ and PP CD11 $\mathrm{c}^{+}$cells (APCs in figure) were enriched by MACS (enrichment of CD11 c cells to about $70 \%$ by FACScan analysis). APCs $\left(5 \times 10^{4}\right.$, $1 \times 10^{4}$, or $\left.1 \times 10^{3}\right)$ were cocultured in 96-well U-bottomed plates with $2 \times 10^{4}$ cells/well high-avidity $(0.001 \mu \mathrm{M} ; \mathbf{A}$ and $\mathbf{C})$ or low-avidity (10 $\mu \mathrm{M}$; B and D) P18-I10-specific CTLs. Negative controls: CTL + Contr APCs, $5 \times 10^{4} \mathrm{CD}_{11 \mathrm{c}^{+}}$APCs isolated from the inguinal LNs or PPs of mice immunized with LT alone were cocultured with $2 \times 10^{4}$ high-avidity (A and $\mathbf{C}$ ) or low-avidity (B and D) P18-I10-specific CTLs; CTL alone, $2 \times 10^{4}$ high-avidity (A and $\mathbf{C}$ ) or low-avidity (B and $\left.\mathbf{D}\right)$ P18I10-specific CTLs were cultured alone; ING APC alone, $5 \times 10^{4}$ CD11Cenriched cells isolated from the inguinal LNs of mice immunized with LT and peptide were cultured alone; 89.6 CTL + APC, $5 \times 10^{4} \mathrm{CD}_{11 \mathrm{c}^{+}}$ APCs isolated from the inguinal LNs of LT- and peptide-immunized mice were cocultured with $2 \times 10^{4}$ high-avidity $(0.001 \mu \mathrm{M}) \mathrm{P} 18$ 89.6A9-specific CTLs (89.6 strain of HIV), which do not cross-react with P18-I10-specific CTLs (IIIB strain of HIV). The level of IFN- $\gamma$ produced by the CTL lines in the supernatant after a 48-hour coculture with CD11c-enriched APCs was measured by semiquantitative ELISA.

\section{Figure 5}

$\mathrm{TCl}$ generated CTL responses in the PPs, SP, and lung. BALB/c mice $(n=5)$ were immunized twice 2 weeks apart with $50 \mu \mathrm{g}$ PCLUS3-IIIB peptide, $10 \mu \mathrm{g} \mathrm{CT}$, and $50 \mu \mathrm{g} \mathrm{CpG}$ by the indicated route of administration for each group as follows: group 1, transcutaneous prime and intrarectal boost; group 2, transcutaneous prime and boost; group 3, subcutaneous (SC) prime and intrarectal boost; group 4, intraperitoneal (IP) prime (peptide and CpG given intraperitoneally and CT administered intrarectally because CT is toxic given intraperitoneally) and intrarectal boost; group 5, intrarectal prime and intrarectal boost; and group 6, no treatment during the first immunization and an intrarectal immunization at the second immunization interval (Single IR). Four weeks after the final immunization, PPs (A), SP (B), and lung (C) were removed, processed, stimulated in vitro with $\mathrm{P} 18$-I10 peptide $(1 \mu \mathrm{M})$ for 7 days, and assayed for cytolytic activity in a ${ }^{51} \mathrm{Cr}$-release assay.

and activate resident $\mathrm{T}$ cells in situ; or (c) a combination of models $\mathrm{a}$ and $\mathrm{b}$ occurs. To evaluate the role of APC trafficking to inductive sites, we conducted three studies: coculture of APCs isolated from DLNs or PPs with antigen-specific T cells as an assay of antigen presentation; analysis of the effects of LT upon activation markers on PP APCs; and monitoring of the migration of APCs to inductive sites of the peripheral and mucosal immune system.

To directly demonstrate that 24 hours after TCI, APCs in the PPs possess sufficient skin-derived antigen to activate antigen-specific $\mathrm{T}$ cells, we conducted an ex vivo coculture experiment in which a T cell line was cultured with PP APCs after TCI. Mice were skin-immunized with LT plus CPG or with LT, CPG, and an HIV peptide (PCLUS318IIIB). Twenty-four hours after TCI, all mice were sacrificed and the
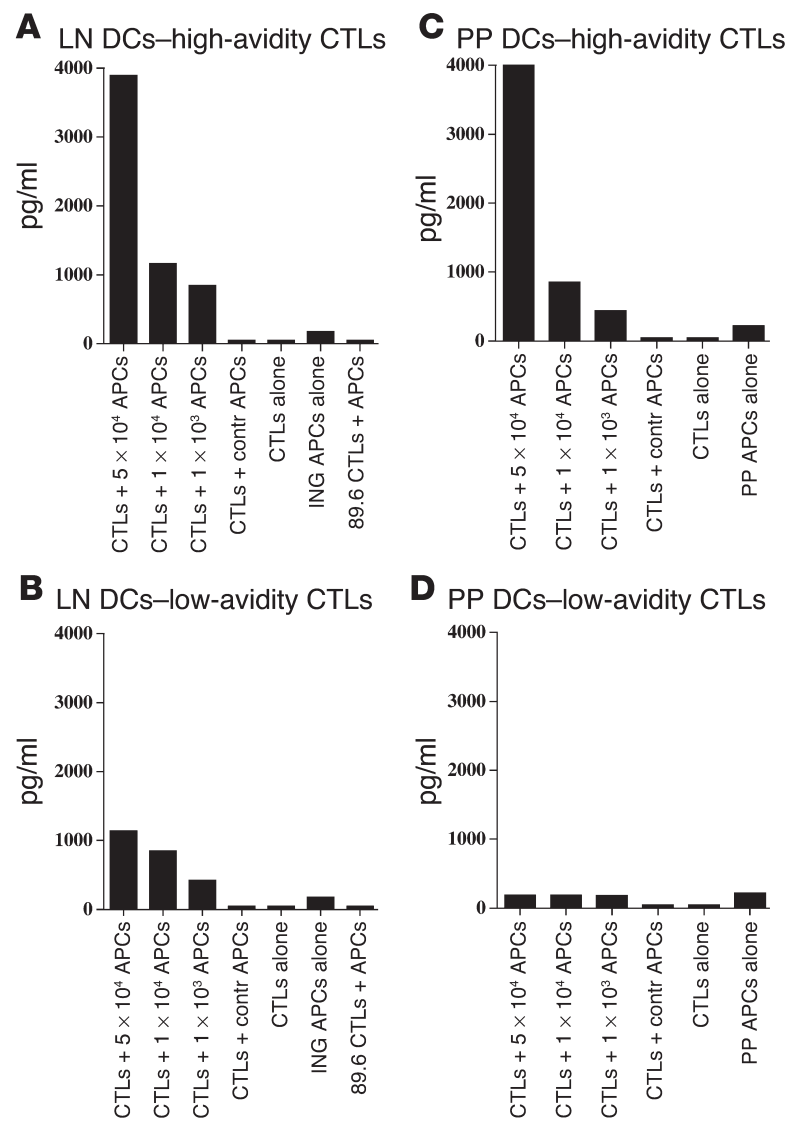


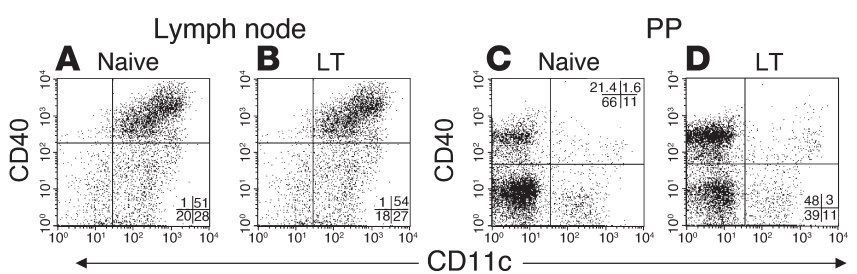

Figure 7

APCs in the PPs have increased cell surface levels of CD40 after TCl with LT. (A-D) C57BL/6 mice were immunized with $50 \mu \mathrm{g}$ of LT and were sacrificed 24 hours later. Inguinal LNs (A and $\mathbf{B})$ and PPs (C and D) were isolated from naive ( $\mathbf{A}$ and $\mathbf{C}$ ) or immunized (B and $\mathbf{D}$ ) mice. Single-cell suspensions were produced and analyzed for levels of CD11c and CD40. Dead cells, B cells $\left(C D 19^{+}\right)$, and T cells $\left(C D 3^{+}\right)$were gated out from the analysis. The percent of cells present in each quadrant are listed.

mononuclear cells from the inguinal LNs and PPs were purified, and then the cell populations were enriched for $\mathrm{CD} 11 \mathrm{c}^{+}$cells using magnetic beads. CD11c-enriched APCs $\left(5 \times 10^{4}, 1 \times 10^{4}\right.$, or $\left.1 \times 10^{3} \mathrm{APCs}\right)$ from animals immunized with PCLUS3-18IIIB by TCI were cocultured in vitro with $1 \times 10^{5} \mathrm{~T}$ cells of a high-avidity $(0.001 \mu \mathrm{M})$ or lowavidity $(10 \mu \mathrm{M}) \mathrm{P} 18$-I10-specific CTL line in 96-well plates. Fortyeight hours later, supernatants were collected and the amount of IFN- $\gamma$ secreted by the HIV-peptide specific CTL line was measured by ELISA (Figure 6). As a control we used CD11 $c^{+}$-enriched APCs from animals TC-immunized with PCLUS3-18IIIB cocultivated with a P18-89.6A9-specific CTL line (89.6 strain of HIV), which does not cross-react with P18-I10-specific CTLs (IIIB strain of HIV), or APCs that were purified from animals immunized with adjuvant alone (LT plus CpG) cocultured with P18-I10-specific LCTLs. Our data indicate that CD11c-enriched APCs from inguinal LNs, without additional antigen added in vitro, can significantly activate both highand low-avidity P18-I10-specific CTL lines (Figure 6, A and B), while APC purified from PPs, without additional antigen added in vitro, can significantly activate the high-avidity P18-I10-specific CTL line only (Figure 6, C and D). The specific T cell cytokine response to the purified mucosal APC populations without further addition of antigen is an indication that the mucosal DCs acquired antigen in vivo from the transcutaneous immunization. The difference between APCs from PPs and the draining inguinal LNs in ability to stimulate low-versus high-avidity CTLs may be an indication that the amount of antigen is less on the more distal PP DCs than on the most proximal DLN DCs. Taken together, these data suggest that one mechanism by which skin immunization induces mucosal immune responses is through the migration of antigen-bearing DCs from the skin to inductive sites of the mucosa. TCI may differently redistribute primed APCs to mucosal and systemic sites, although this concept was not directly addressed.

LT application on the skin activates DCs to migrate from the skin into the DLNs but not to distal LNs. LT also upregulates maturation markers such as CD86 on the surface of APCs found in the $\mathrm{DLNs}^{18}$. However, it was unknown if skin-applied LT directly affects APCs located in the inductive sites of the gut mucosa (i.e., PPs). Mice were immunized with an LT patch and sacrificed 24 hours later. Flow cytometry analysis of APCs located in the DLNs of LT-treated mice showed an increase in CD86 (data not shown; consistent with previous studies [18]) but not CD40 (Figure 7, A and $\mathrm{B}$ ) on the $\mathrm{CD} 11 \mathrm{c}^{+}$population compared with APCs from naive animals. In contrast, on APCs isolated from PPs of LT-treated mice, levels of CD86 (data not shown) were unchanged, whereas an increase in levels of CD40 was observed in both the CD11 $\mathrm{c}^{+}$population (88\% increase; of the total gated populations, $1.6 \%$ $\mathrm{CD} 11 \mathrm{c}^{+} \mathrm{CD} 40^{+}$cells detected in the naive group's PPs compared with $3.0 \% \mathrm{CD} 11 \mathrm{c}^{+} \mathrm{CD} 40^{+}$cells detected in the LT-treated group's PPs) and the CD11 $c^{-}$population (124\% increase; of the total gated populations, $21.4 \% \mathrm{CD} 11 \mathrm{c}^{-} \mathrm{CD} 40^{+}$cells detected in the naive group's PPs compared with $48 \% \mathrm{CD} 11 \mathrm{c}^{-} \mathrm{CD} 40^{+}$cells detected in the LT-treated group's PPs) (Figure 7, C and D). The addition of CPG oligodeoxynucleotide with LT in the immunization regimen did not alter the population compared with LT alone (data not shown). These results demonstrated that skin-applied LT has a direct effect upon APCs resident in the PPs and suggested that APCs can migrate from the skin to the PPs.

We have shown that APCs migrate directly to the DLNs and do not traffic to other peripheral LNs within 72 hours after application of an LT patch (18). Our functional data here (Figure 6) showed that APCs carrying skin-applied antigen migrated from the skin to the inductive sites of the gut mucosa. We sought to visually confirm this migration from the skin to mucosal sites (i.e., PPs) by looking for PP APCs containing skin-derived and fluorescently labeled LT after TCI. Mice were left untreated (naive) or were immunized with fluorescent LT (AF-LT). Then, 24 (data not shown) and 48 (Figure 8) hours later, inguinal, superficial cervical, and mesenteric LNs, SPs, and PPs were analyzed for the presence of resident APCs containing fluorescent LT. As we have shown previously (18), CD $11 \mathrm{c}^{+}$MHC class II ${ }^{\mathrm{hi}} \mathrm{APCs}$ in the (inguinal) DLNs contained LT after TCI with the fluorescent antigen (Figure 8, B and C). LNs (superficial cervical and mesenteric) that did not drain the site of immunization and the SP were negative for labeled LT
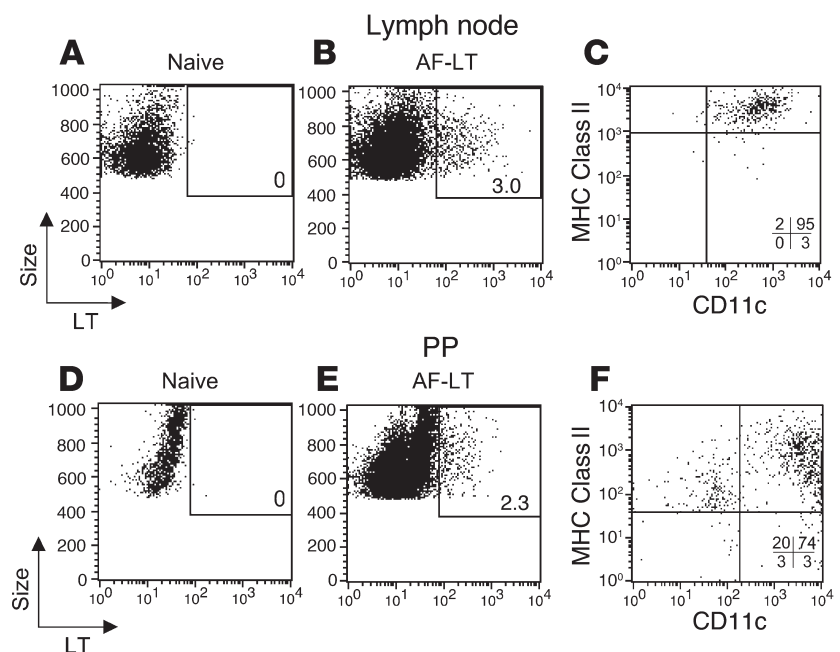

\section{Figure 8}

APCs in the PPs contain skin-derived fluorescent LT after TCI. (A-F) BALB/c mice were left untreated (A and $\mathbf{D})$ or were immunized with $50 \mu \mathrm{g}$ of Alexa Fluor 488-conjugated LT (AF-LT; B, C, E, and F). Forty-eight hours later, inguinal LNs and PPs were isolated and analyzed for cell populations containing AF-LT (A, B, D, and E). The CD11C, MHC class II ( $\left.\mathrm{H}-2 \mathrm{I}-\mathrm{A}^{\mathrm{d}}\right)$ surface expression of AF-LT-positive cells was determined for both inguinal LN (C) and PP (F) cells. Similar results were observed 24 hours after application of AF-LT. The percent of AF-LT-positive cells are listed in A, B, D, and E. The percent of cells present in each quadrant are listed in $\mathbf{C}$ and $\mathbf{F}$. 
(data not shown). APCs that had "picked up" the fluorescent LT were also detected in the PPs (2.3\%; Figure 8E) compared with none in the naive control PPs (Figure 8D). Interestingly, a majority of the $\mathrm{LT}^{+}$cells located in the PPs were CD11 $\mathrm{c}^{+}$and $\mathrm{MHC}$ class $\mathrm{II}^{+}$(Figure $8 \mathrm{~F})$. Resident cells in the PPs did not acquire cell-free fluorescent antigen or exosomes (38) containing fluorescent LT through uptake in the PPs, as nondraining LN and SP cell populations were negative for $\mathrm{LT}^{+}$cells and would have also taken up similar quantities of cell-free antigen through normal routes of lymph and blood circulation. Fluorescent LT was observed to be concentrated in vesicles located in the cytoplasm of the APCs and not on the surface of the cells (data not shown). The PPs also contained a small population of non-B (CD19-), non- $\left(C D 3 \varepsilon^{-}\right)$, nonmacrophage $\left(\mathrm{F} 4 / 80^{-}\right)$, large granular cells of an unknown phenotype that contained LT (Figure $8 \mathrm{~F}$ ). Taken together, these results suggested that APCs have a direct migration route from the skin to the gut mucosa that can be initiated by the application of LT on the skin and in which skin-derived antigen is presented directly in the gut mucosa to induce mucosal immune responses.

\section{Discussion}

In this study, we demonstrated that the application of antigen on the skin is an effective means for inducing robust systemic and mucosal CD8 ${ }^{+}$CTL responses. Mucosal immune responses are considered desirable for their ability to stop pathogens at the point of entry at mucosal surfaces and, in the case of influenza infections, for CTLs to mediate in viral clearance (39). Parenteral immunization with nonreplicating HIV agents often fail to contribute to specific mucosal immune responses, and only immunization by mucosal routes can induce optimal protection against mucosal challenge $(4,12,40)$, although most licensed vaccines can protect against mucosal pathogens after intramuscular or subcutaneous injection of antigen (41-43). Because skin immunization generates mucosal responses in the gut, lung, saliva (15), and female reproductive tract (15), it appears to be a unique route by which to deliver antigens to multiple mucosal sites and differs from traditional immunization routes that induce compartmentalized mucosal responses. Examples of compartmentalized responses include those to intrarectal and oral immunizations, which induce mucosal responses mainly in the gut, and to intranasal immunizations, which produce mucosal responses located mainly in the lung and nasal-associated lymphoid tissues. The mechanism by which TCI induces immune responses in both systemic and multiple mucosal compartments, each having very different lymphocyte homing markers (44-47), is not known and remains a subject of investigation. The current results suggest that the migration of DCs from skin to both systemic and mucosal compartments may provide such a mechanism. Furthermore, because the mucosa and skin share similar elements such as DCs, secretory organs, the presence of IgA such as that found in sweat glands (48), and microorganisms coated with immunoglobulins including IgA and secretory component of IgA (49), and can prime and boost a mucosal immune response, it is seems reasonable to consider the skin as behaving like a "distant relative" of a mucosal surface.

The effectiveness of any prophylactic immunization strategy in the infectious disease setting is its ability to protect against challenge by a live organism. Several TCI studies have demonstrated the potency of this route of administration against infectious disease agents such as bacterial toxins $(13,14,16,24,50)$, live bacteria (51), and live viruses $(19,52)$. Protective immunity mediated by antibody against live influenza virus challenge was also demonstrated using a similar but slightly different skin immunization strategy in which dry powder containing antigen and adjuvant were driven into the skin by a gaspowered gun $(53,54)$. We have extended these findings by demonstrating increased protection in skin immunized mice against a mucosal (i.e., intrarectal) challenge with a live vaccinia virus vector. As the recombinant vaccinia does not incorporate HIV-1 gp160 into the virus particle and thus is not sensitive to neutralization by antigp160, the reduction in viral load was solely due to cell-mediated effector mechanisms, in contrast to the other TCI challenge studies in which protective responses were mediated mainly through humoral immune components. Although the protection seen in these experiments was a $2-\log _{10}$ reduction in viral PFU, slightly less than the 3- to 4-log reduction we have seen with four doses of peptide and LT given intrarectally (12), the strong dependence on the number of immunizations makes these results difficult to compare directly. Although the recombinant vaccinia expressing HIV-1 gp160 is less virulent than wild-type vaccinia, because the insert replaces the tyrosine kinase gene, $\mathrm{T}$ cells have been shown to protect against death from lethal vaccinia virus challenge (55).

Mucosal and systemic CTL responses were produced after TCI with antigen administered at several anatomical sites. Responses were greater in magnitude when antigen was applied to the abdomen or back compared with the ear, although the epidermis of the ear, abdomen, and back has a similar density and distribution of DCs $(56,57)$. After TCI, these sites also have equivalent "immunopotential" to elicit similar levels of antibody (58). These results suggest that TCI targets mucosal responses regardless of the site of administration and that immunogens can be applied anywhere on the skin where DCs are present to induce a systemic or mucosal response. However, local responses in the DLNs proximal to the site of TCI may be greater in magnitude than those of distal immunization sites (data not shown), and this may be an important consideration in determining the location of antigen placement on the skin when immune responses need to be directed to a localized anatomical site (e.g., for cancer treatment).

Unmethylated oligodeoxynucleotides containing CpG motifs are effective immunomodulating agents and act as adjuvants to elicit a predominantly $\mathrm{Th} 1 \mathrm{CD} 4^{+} \mathrm{T}$ cell response to coadministered antigens in mice (30). CpGs were combined with CT in our initial immunization regimen, as it was believed that CT by itself would be unable to elicit a robust Th1-directed CTL response (59-61). CT and LT were able to act as adjuvants in eliciting systemic and mucosal CTL responses with or without the addition of $\mathrm{CPG}$ oligodeoxynucleotides, but CTL levels were increased by the inclusion of CPG oligodeoxynucleotides. CT and LT also induced functionally similar levels of protective immunity against virus challenge. The Th2 bias reported for immunizations using CT as an adjuvant $(59,61,62)$ may be related to a number of factors in addition to the known inhibition of IL-12 production (63), including the route of delivery, the coadministered antigen, and the microenvironment and its effects on the cytokines and chemokines produced by APCs after encountering the adjuvant and antigen. Interestingly, CT as an adjuvant on the skin primes a CTL response in the absence of IL-12 (21), a known promoter of Th1 CD4 ${ }^{+} \mathrm{T}$ cells and $\mathrm{CD}^{+} \mathrm{CTL}$ development (64) and an enhancer of the activation of naive $\mathrm{CD}^{+} \mathrm{T}$ cells (65). However, IL-12 produced by DCs is not required for the in vivo priming of CTLs (66). Although still controversial, a number of the DC parameters (receptors, cytokines, chemokines, etc.) that direct Th1 and Th2 lymphocyte develop- 
ment have been identified (67-71). However, the in vivo effects of CT and LT on skin-derived APC and their effect upon Th1 and Th2 lymphocyte development are unknown and are under investigation. From our study and results reported elsewhere $(24,14,18,21)$, it would appear that the skin contains and provides the appropriate microenvironment for both CT and LT to act as adjuvants in eliciting an effective Th1 response as well as a Th2 response directed against protein-based antigens. For application to humans, the $\mathrm{CpG}$-containing sequence motifs effective in humans are different from those active in mice, but most of the same effects can be elicited with the appropriate sequence $(30,72)$. However, there may still be differences in outcome in view of the fact that there are differences in TLR9 expression in mice and humans. In mice, both plasmacytoid DCs and myeloid DCs express TLR9, while in humans only plasmacytoid DCs, not myeloid DCs, express this receptor for CpG oligodeoxynucleotides (71, 73-76).

It has been proposed and subsequently demonstrated that priming an immune response in a specific inductive site by one method of immunization (e.g., transcutaneously) should further modulate or enhance a subsequent immune response developing through the same inductive site by an alternative route of immunization (e.g., intrarectally) (77). We utilized this concept to ascertain the potential of priming by one mucosal route of immunization (transcutaneously or intrarectally), boosting with a second (intrarectally or transcutaneously), and then measuring the effects by the level of mucosal CTLs elicited using the various combinations. Overall, the responses with the greatest magnitude found in the PPs, lung, and SP were all primarily dependent upon the priming route (intrarectal for PPs, transcutaneous for lung, and intraperitoneal for SP) and secondarily on the boosting route. Transcutaneous immunization was able to boost an intrarectally primed response and vice versa. These results further support the concept that transcutaneous administration is an excellent route for initiating a mucosal immune response, but raised the question of how intrarectal and transcutaneous immunization can target similar inductive sites and modulate each other's responses when the two anatomical sites of antigen application are far removed from each other and the sites of immune induction (i.e., PPs for intrarectal and DLNs for transcutaneous) are not known to be the same.

As presented above, three models based on known paradigms were put forth to explain how TCI primes and amplifies mucosal CTL responses: (a) APCs migrate from the skin to the regional DLNs into $T$ cell-rich areas and prime and activate resident $T$ cells, and then the T cells migrate from the regional DLNs to peripheral and mucosal effector sites; (b) APCs migrate from the skin to the PPs (or other mucosal inductive sites) and activate $\mathrm{T}$ cells in situ; and (c) a combination of (a) and (b). We focused on developing models to determine if APCs can migrate from the skin to the PPs by assessing the migratory properties of skin-resident APCs after TCI. By using an APC/T cell coculture study and tracking migrating APCs by flow cytometry, we demonstrated that CD $11 c^{+}$APCs carrying skin-derived antigens can be isolated and identified in the PPs within 24 hours of topical application of antigen. Our data are consistent with those of Enioutina et al. (78), who demonstrated that an increase in injected bone marrow-derived CD $11 \mathrm{c}^{+}$DC numbers could be found in PPs after the cells had been treated ex vivo with vitamin D3, CT, or forskolin and then injected intravenously or intradermally. Our in vivo DC tracking results are also consistent with recent reports suggesting that DCs located in the mucosa inductive sites are mainly responsible for imprinting gut-homing potential to $\mathrm{T}$ cells (79-81). In addition, a small population of CD11 $\mathrm{c}^{-}$cells was identified that contained skin-derived antigen, were located in the PPs, and were not B cells (CD19-), T cells (CD3 $\left.\varepsilon^{-}\right)$, or macrophages. The identity and functional significance of this population in the PPs is unknown and is under investigation. In view of the recent study by Allan et al. (82) distinguishing between Langerhans cells and $\mathrm{CD} 8 \mathrm{a}^{+} \mathrm{DC}$ in viral immunity, it would be of interest to know which of these populations is involved in the transport of antigen to the PPs. Our current data do not allow us to distinguish these subpopulations, but future studies should allow us to resolve these subsets.

Although we did not address the hypothesis of $\mathrm{T}$ cell migration from regional DLNs to mucosal effector sites for the induction of mucosal responses after TCI, it was clear from literature on contact sensitization (83) and from our own studies (18) that after they are activated, skin-derived APCs migrate to the regional DLNs and activate $T$ cells to migrate to peripheral sites that may include the gut mucosa. T cell activation in the DLNs is mediated by migratory APCs that through direct cell-to-cell contact, cytokine secretion, and chemokine secretion alter the phenotype of lymphocytes to exit the DLNs through the efferent lymph and home to a variety anatomical sites as determined by their surface marker expression and the different chemokine and adhesion molecule expression of peripheral lymphoid and nonlymphoid tissue (84-88). Although recent reports suggest that the gut-homing tropism of T cells may be directed mainly by DCs resident in the PPs or mesenteric LNs and not in peripheral LNs (79-81), we have observed that after topical application of LT, a majority of T cells present in the skin DLNs express the peripheral lymphocyte homing markers $\beta 1$ integrin and CD62L, while a small population of $\mathrm{T}$ cells express the mucosal homing marker $\alpha_{4} \beta_{7}{ }^{+}$(data not shown). In the context of topical delivery, LT may act as a mucosal adjuvant, providing a specific signal for DCs in the DLNs to activate the expression of mucosal homing receptors on resident naive $\mathrm{T}$ cells. Thus, the APC, microenvironmental signals, and/or adjuvant may promote $T$ cells to modulate homing receptor expression with a specificity for a wide range of anatomical migratory destinations. However, from our studies and published reports, it appears that APC migration to mucosal inductive sites is the main mechanism in vivo by which robust mucosal immune responses are produced after TCI.

\section{Acknowledgments}

We thank Bernard Moss and Patricia Earl for providing the vaccinia virus carrying the gene for HIV-1 gp160 for the isolate IIIB. We thank Andy Blauvelt and Brian Kelsall for critical reading of the manuscript and for helpful suggestions. We thank Tanya Scharton-Kersten for helpful advice.

Received for publication October 9, 2003, and accepted in revised form January 13, 2004.

Address correspondence to: Igor M. Belyakov, Molecular Immunogenetics and Vaccine Research Section, Vaccine Branch, National Cancer Institute, National Institutes of Health, Bethesda, Maryland 20892-1578, USA. Phone: (301) 435-8341; Fax: (301) 402-0549; E-mail: belyakov@mail.nih.gov.

Igor M. Belyakov and Scott A. Hammond contributed equally to this work. 
1. Lehner, T., et al. 1996. Protective mucosal immunity elicited by targeted iliac lymph node immunization with a subunit SIV envelope and core vaccine in macaques. Nat. Med. 2:767-775.

2. Belyakov, I.M., et al. 1998. Mucosal immunization with HIV-1 peptide vaccine induces mucosal and systemic cytotoxic $\mathrm{T}$ lymphocytes and protective immunity in mice against intrarectal recombinant HIVvaccinia challenge. Proc. Natl. Acad. Sci. U. S. A. 95:1709-1714

3. Berzofsky, J.A., et al. 1999. Approaches to improve engineered vaccines for human immunodeficiency virus (HIV) and other viruses that cause chronic infections. Immunol. Rev. 170:151-172.

4. Murphey-Corb, M., et al. 1999. Selective induction of protective MHC class I restricted CTL in the intestinal lamina propria of rhesus monkeys by transient SIV infection of the colonic mucosa. J. Immunol. 162:540-549.

5. Berzofsky, J.A., Ahlers, J.D., Belyakov, I.M. 2001. Strategies for designing and optimizing new generation vaccines. Nat. Rev. Immunol. 1:209-219.

6. Ahlers, J.D., Belyakov, I.M., and Berzofsky, J.A. 2003. Cytokine, chemokine and costimulatory molecule modulation to enhance efficacy of HIV vaccines. Curr. Mol. Med. 3:285-301.

7. Schmitz, J.E., et al. 1999. Control of viremia in simian immunodeficiency virus infection by CD8+ lymphocytes. Science. 283:857-860.

8. Jin, X., et al. 1999. Dramatic rise in plasma viremia after CD8 $+\mathrm{T}$ cell depletion in simian immunodeficiency virus-infected macaques. J. Exp. Med. 189:991-998.

9. Belyakov, I.M., et al. 2001. Mucosal AIDS vaccine reduces disease and viral load in gut reservoir and blood after mucosal infection of macaques. Nat. Med. 7:1320-1326

10. Ahlers, J.D., Belyakov, I.M., Thomas, E.K., and Berzofsky, J.A. 2001. High-affinity T helper epitope induces complementary helper and APC polarization, increased CTL, and protection against viral infection. J. Clin. Invest. 108:1677-1685.

11. Ahlers, J.D., Belyakov, I.M., Matsui, S., and Berzofsky, J.A. 2001. Mechanisms of cytokine synergy essential for vaccine protection against viral challenge. Int. Immunol. 13:897-908.

12. Belyakov, I.M., et al. 1998. The Importance of local mucosal HIV-specific CD8+ cytotoxic T lymphocytes for resistance to mucosal-viral transmission in mice and enhancement of resistance by local administration of IL-12. J. Clin. Invest. 102:2072-2081.

13. Glenn, G.M., Scharton-Kersten, T., Vassell, R., Matyas, G.R., and Alving, C.R. 1999. Transcutaneous immunization with bacterial ADP-ribosylating exotoxins as antigens and adjuvants. Infect. Immun. 67:1100-1106

14. Glenn, G.M., et al. 1998. Transcutaneous immunization with cholera toxin protects mice against lethal mucosal toxin challenge. J. Immunol. 161:3211-3214

15. Berry, L.J., et al. 2004. Transcutaneous immunization with combined cholera toxin and CPG adjuvant protects against Chlamydia muridarum genital tract infection. Infect. Immun. 72:1019-1028.

16. Yu, J., et al. 2002. Transcutaneous immunization using colonization factor and heat-labile enterotoxin induces correlates of protective immunity for enterotoxigenic Escherichia coli. Infect. Immun. 70:1056-1068

17. Guerena-Burgueno, F., et al. 2002. Safety and immunogenicity of a prototype enterotoxigenic Escherichia coli vaccine administered transcutaneously. Infect. Immun. 70:1874-1880

18. Guebre-Xabier, M., et al. 2003. Immunostimulant patch containing heat-labile enterotoxin from Escherichia coli enhances immune responses to injected influenza virus vaccine through activation of skin dendritic cells. J. Virol. 77:5218-5225.
19. Godefroy, S., et al. 2003. Immunization onto shaved skin with a bacterial enterotoxin adjuvant protects mice against respiratory syncytial virus (RSV). Vaccine. 21:1665-1671.

20. Seo, N., et al. 2000. Percutaneous peptide immunization via corneum barrier-disrupted murine skin for experimental tumor immunoprophylaxis. Proc. Natl. Acad. Sci. U. S. A. 97:371-376.

21. Kahlon, R., et al. 2003. Optimization of epicutaneous immunization for the induction of CTL. Vaccine. 21:2890-2899.

22. Hammond, S.A., Walwender, D., Alving, C.R., and Glenn, G.M. 2001. Transcutaneous immunization: $\mathrm{T}$ cell responses and boosting of existing immunity. Vaccine. 19:2701-2707.

23. Baca-Estrada, M.E., et al. 2002. The haemopoietic growth factor, Flt $3 \mathrm{~L}$, alters the immune response induced by transcutaneous immunization. Immunol ogy. 107:69-76.

24. Scharton-Kersten, T., et al. 2000. Transcutaneous immunization with bacterial ADP-ribosylating exotoxins, subunits, and unrelated adjuvants. Infect. Immun. 68:5306-5313.

25. Glenn, G.M., et al. 2000. Transcutaneous immunization: a human vaccine delivery strategy using a patch. Nat. Med. 6:1403-1406.

26. Glenn, G.M., et al. 2003. Transcutaneous immunization and immunostimulant strategies: capitalizing on the immunocompetence of the skin. Expert Rev. Vaccines. 2:253-267.

27. Fong, L., and Engleman, E.G. 2000. Dendritic cells in cancer immunotherapy. Annu. Rev. Immunol. 18:245-273.

28. Berzofsky, J.A., et al. 1991. Construction of peptides encompassing multideterminant clusters of HIV envelope to induce in vitro $\mathrm{T}$-cell responses in mice and humans of multiple MHC types. J. Clin. Invest. 88:876-884.

29. Takahashi, H., et al. 1988. An immunodominant epitope of the HIV gp160 envelope glycoprotein recognized by class I MHC molecule-restricted murine cytotoxic T lymphocytes. Proc. Natl. Acad. Sci. U. S. A. 85:3105-3109.

30. Krieg, A.M. 2002. CpG motifs in bacterial DNA and their immune effects. Annu. Rev. Immunol. 20:709-760.

31. Belyakov, I.M., et al. 1998. Induction of mucosal CTL response by intrarectal immunization with a replication-deficient recombinant vaccinia virus expressing HIV 89.6 envelope protein. J. Virol. 72:8264-8272.

32. Belyakov, I.M., Moss, B., Strober, W., and Berzofsky, J.A. 1999. Mucosal vaccination overcomes the barrier to recombinant vaccinia immunization caused by preexisting poxvirus immunity. Proc. Natl. Acad. Sci. U. S. A. 96:4512-4517.

33. Bukreyev, A., Belyakov, I.M., Berzofsky, J.A., and Murphy, B.R. 2001. Granulocyte-macrophage colonystimulating factor expressed by recombinant respiratory syncytial virus attenuates viral replication and increases the level of pulmonary antigen-presenting cells. J. Virol. 75:12128-12140.

34. Belyakov, I.M., et al. 2001. Activating CTL precursors to reveal CTL function without skewing the repertoire by in vitro expansion. Eur. J. Immunol. 31:3557-3566.

35. Klinman, D.M., Barnhart, K.M., and Conover, J. 1999. CpG motifs as immune adjuvants. Vaccine. 17:19-25

36. Horner, A.A., et al. 2001. Immunostimulatory DNAbased vaccines elicit multifaceted immune responses against HIV at systemic and mucosal sites. J. Immunol. 167:1584-1591.

37. Earl, P.L., Koenig, S., and Moss, B. 1991. Biological and immunological properties of human immunodeficiency virus type 1 envelope glycoprotein: analysis of proteins with truncations and deletions expressed by recombinant vaccinia viruses. J. Virol. 65:31-41.

38. Thery, C., et al. 2001. Proteomic analysis of dendrit- ic cell-derived exosomes: a secreted subcellular compartment distinct from apoptotic vesicles. J. Immunol. 166:7309-7318

39. McMichael, A.J., Askonas, B.A., Webster, R.G., and Laver, W.G. 1982. B-cell or T-cell immunity? Immunol. Today. 3:255-260.

40. Kaul, D., and Ogra, P.L. 1998. Mucosal responses to parenteral and mucosal vaccines. Dev. Biol. Stand. 95:141-146.

41. Moss, B. 1991. Vaccinia virus: a tool for research and vaccine development. Science. 252:1662.

42. Bukreyev, A., and Belyakov, I.M. 2002. Expression of immunomodulating molecules by recombinant viruses: can the immunogenicity of live virus be improved? Expert Rev. Vaccines. 1:233-244.

43. Osterhaus, A.D., and de Vries, P. 1992. Vaccination against acute respiratory virus infections and measles in man. Immunobiology. 184:180-192.

44. Csencsits, K.L., Jutila, M.A., and Pascual, D.W. 1999. Nasal-associated lymphoid tissue: phenotypic and functional evidence for the primary role of peripheral node addressin in naive lymphocyte adhesion to high endothelial venules in a mucosal site. J. Immunol. 163:1382-1389.

45. Jahnsen, F.L., Farstad, I.N., Aanesen, J.P., and Brandtzaeg, P. 1998. Phenotypic distribution of T cells in human nasal mucosa differs from that in the gut. Am. J. Respir. Cell Mol. Biol. 18:392-401.

46. Xu, B., et al. 2003. Lymphocyte homing to bronchusassociated lymphoid tissue (BALT) is mediated by L-selectin/PNAd, alpha4beta1 integrin/VCAM-1, and LFA-1 adhesion pathways. J. Exp. Med. 197:1255-1267.

47. Williams, M.B., and Butcher E.C. 1997. Homing of naive and memory T lymphocyte subsets to Peyer's patches, lymph nodes, and spleen. J. Immunol. 159:1746-1752.

48. Okada, T., Konishi, H., Ito, M., Nagura, H., and Asai, J. 1988. Identification of secretory immunoglobulin A in human sweat and sweat glands. J. Invest. Dermatol. 90:648-651.

49. Metze, D., Kersten, A., Jurecka, W., and Gebhart, W. 1991. Immunoglobulins coat microorganisms of skin surface: a comparative immunohistochemical and ultrastructural study of cutaneous and oral microbial symbionts. J. Invest. Dermatol. 96:439-445.

50. Beignon, A.S., Briand, J.P., Muller, S., and Partidos, C.D. 2001. Immunization onto bare skin with heatlabile enterotoxin of Escherichia coli enhances immune responses to coadministered protein and peptide antigens and protects mice against lethal toxin challenge. Immunology. 102:344-351.

51. Shi, Z., et al. 2001. Protection against tetanus by needle-free inoculation of adenovirus-vectored nasal and epicutaneous vaccines. J. Virol. 75:11474-11482.

52. El-Ghorr, A.A., Williams, R.M., Heap, C., and Norval, M. 2000. Transcutaneous immunisation with herpes simplex virus stimulates immunity in mice. FEMS Immunol. Med. Microbiol. 29:255-261.

53. Chen, D., et al. 2001. Epidermal powder immunization induces both cytotoxic T-lymphocyte and antibody responses to protein antigens of influenza and hepatitis B viruses. J. Virol. 75:11630-11640.

54. Chen, D., Endres, R.L., Erickson, C.A., Maa, Y.F., and Payne, L.G. 2002. Epidermal powder immunization using non-toxic bacterial enterotoxin adjuvants with influenza vaccine augments protective immunity. Vaccine. 20:2671-2679.

55. Belyakov, I.M., et al. 2003. Shared modes of protection against poxivirus infection by attenuated and conventional smallpox vaccine viruses. Proc. Natl. Acad. Sci. U. S. A. 100:9458-9463.

56. Gebara, G., Magalhaes-Pinto, R., Tendler, M., Queiroz-da-Cruz, M., and Oliveira-Lima, A. 1986. Distribution of Langerhans cells in Swiss Webster mouse skin. Braz. J. Med. Biol. Res. 19:131-133.

57. Bergstresser, P.R., Fletcher, C.R., and Streilein, J.W. 1980. Surface densities of Langerhans cells in relation to rodent epidermal sites with special immuno- 
logic properties. J. Invest. Dermatol. 74:77-80.

58. Scharton-Kersten, T., et al. 1999. Principles of transcutaneous immunization using cholera toxin as an adjuvant. Vaccine. 17:S37-S43.

59. Marinaro, M., et al. 1995. Mucosal adjuvant effect of cholera toxin in mice results from induction of $\mathrm{T}$ helper 2 (Th2) cells and IL-4. J. Immunol. 155:4621-4629.

60. Gagliardi, M.C., et al. 2000. Cholera toxin induces maturation of human dendritic cells and licences them for Th2 priming. Eur. J. Immunol. 30:2394-2403.

61. Boyaka, P.N., et al. 2003. Chimeras of labile toxin one and cholera toxin retain mucosal adjuvanticity and direct Th cell subsets via their B subunit. J. Immunol. 170:454-462.

62. Belyakov, I.M., Ahlers, J.D., Clements, J.D., Strober, W., and Berzofsky, J.A. 2000. Interplay of cytokines and adjuvants in the regulation of mucosal and systemic HIV-specific cytotoxic $\mathrm{T}$ lymphocytes. J. Immunol. 165:6454-6462.

63. Braun, M.C., He, J., Wu, C.-Y., and Kelsall, B.L. 1999. Cholera toxin suppresses interleukin (IL)-12 production and IL-12 receptor B1 and B2 chain expression. J. Exp. Med. 189:541-552.

64. Gately, M.K., et al. 1998. The interleukin-12/interleukin-12-receptor system: role in normal and pathologic immune responses. Annu. Rev. Immunol. 16:495-521.

65. Schmidt, C.S., and Mescher, M.F. 2002. Peptide antigen priming of naive, but not memory, CD8 T cells requires a third signal that can be provided by IL-12. J. Immunol. 168:5521-5529.

66. Wan Y., et al. 2001. Dendritic cell-derived IL-12 is not required for the generation of cytotoxic, IFNgamma-secreting, CD8+ CTL in vivo. J. Immunol. 167:5027-5033.

67. Moser, M., and Murphy, K.M. 2000. Dendritic cell regulation of $\mathrm{T}_{\mathrm{H}} 1-\mathrm{T}_{\mathrm{H}} 2$ development. Nat. Immunol. 1:199-205.

68. Langenkamp, A., Messi, M., Lanzavecchia, A., and Sallusto, F. 2000. Kinetics of dendritic cell activation: impact on priming of $\mathrm{T}_{\mathrm{H}} 1, \mathrm{~T}_{\mathrm{H}} 2$ and nonpolarized $\mathrm{T}$ cells. Nat. Immunol. 1:311-316.

69. Pulendran, B., Banchereau, J., Maraskovsky, E., and Maliszewski, C. 2001. Modulating the immune response with dendritic cells and their growth factors. Trends Immunol. 22:41-47.

70. Huang, Q., et al. 2001. The plasticity of dendritic cell responses to pathogens and their components. Science. 294:870-875.

71. Boonstra, A., et al. 2003. Flexibility of mouse classical and plasmacytoid-derived dendritic cells in directing T helper type 1 and 2 cell development: dependency on antigen dose and differential toll-like receptor ligation. J. Exp. Med. 197:101-109.

72. Verthelyi, D., et al. 2002. CpG oligodeoxynucleotides as vaccine adjuvants in primates. J. Immunol. 168:1659-1663.

73. Sparwasser, T., Vabulas, R.M., Villmow, B., Lipford, G.B., and Wagner, H. 2000. Bacterial CpG-DNA activates dendritic cells in vivo: $T$ helper cell-independent cytotoxic $\mathrm{T}$ cell responses to soluble proteins. Eur. J. Immunol. 30:3591-3597.

74. Asselin-Paturel, C., et al. 2001. Mouse type I IFN-producing cells are immature APCs with plasmacytoid morphology. Nat. Immunol. 2:1144-1150.

75. Kadowaki, N., et al. 2001. Subsets of human dendritic cell precursors express different toll-like receptors and respond to different microbial antigens. J. Exp. Med. 194:863-869.

76. Hornung, V., et al. 2002. Quantitative expression of toll-like receptor 1-10 mRNA in cellular subsets of human peripheral blood mononuclear cells and sensitivity to CpG oligodeoxynucleotides. J. Immunol. 168:4531-4537.

77. Guy, B., Fourage, S., Hessler, C., Sanchez, V., and Millet, M.J. 1998. Effects of the nature of adjuvant and site of parenteral immunization on the serum and mucosal immune responses induced by a nasal boost with a vaccine alone. Clin. Diagn. Lab Immunol. 5:732-736.

78. Enioutina, E.Y., Visic, D., and Daynes, R.A. 2000. The induction of systemic and mucosal immune responses to antigen-adjuvant compositions administered into the skin: alterations in the migratory properties of dendritic cells appears to be important for stimulating mucosal immunity. Vaccine. 18:2753-2767.

79. Campbell, D.J., and Butcher, E.C. 2002. Rapid acquisition of tissue-specific homing phenotypes by $\mathrm{CD} 4^{+}$ $T$ cells activated in cutaneous or mucosal lymphoid tissues. J. Exp. Med. 195:135-141.

80. Mora, J.R., et al. 2003. Selective imprinting of guthoming T cells by Peyer's patch dendritic cells. Nature. 424:88-93.

81. Johansson-Lindbom, B., et al. 2003. Selective generation of gut tropic $\mathrm{T}$ cells in gut-associated lymphoid tissue (GALT): requirement for GALT dendritic cells and adjuvant. J. Exp. Med. 198:963-969.

82. Allan, R.S., et al. 2003. Epidermal viral immunity induced by CD8alpha+ dendritic cells but not by Langerhans cells. Science. 301:1925-1928.

83. Kripke, M.L., Munn, C.G., Jeevan, A., Tang, J.M., and Bucana, C. 1990. Evidence that cutaneous antigenpresenting cells migrate to regional lymph nodes during contact sensitization. J. Immunol. 145:2833-2838.

84. Langenkamp, A., et al. 2003. Kinetics and expression patterns of chemokine receptors in human CD4+ T lymphocytes primed by myeloid or plasmacytoid dendritic cells. Eur. J. Immunol. 33:474-482.

85. Butcher, E.C., and Picker, L.J. 1996. Lymphocyte homing and homeostasis. Science. 272:60-66.

86. Brandtzaeg, P., Farstad, I.N., and Haraldsen, G. 1999. Regional specialization in the mucosal immune system: primed cells do not always home along the same track. Immunol. Today. 20:267-277.

87. Kunkel, E.J., and Butcher, E.C. 2002. Chemokines and the tissue-specific migration of lymphocytes. Immunity. 16:1-4.

88. Belyakov, I.M., and Berzofsky, J.A. 2004. Immunobiology of mucosal HIV infection and the basis for development of a new generation of mucosal AIDS vaccines. Immunity. 20:247-253. 